
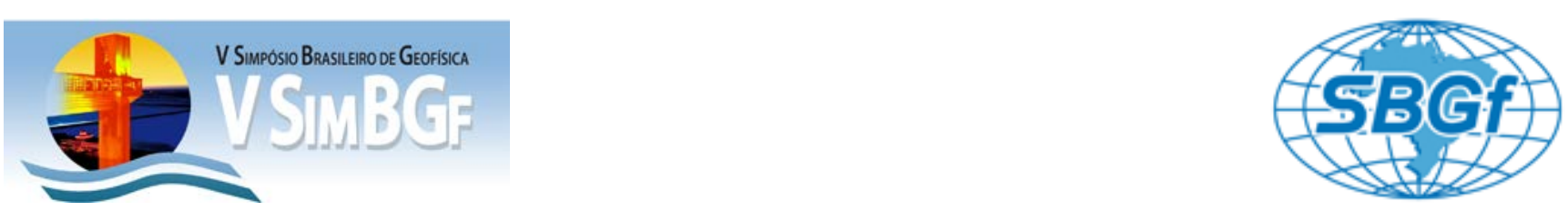

\title{
Origem e evolução geotectônica do manto abissal exumado da Cadeia Peridotítica de São Pedro e São Paulo, Oceano Atlântico Equatorial
}

Origin and geotectonic evolution of the abyssal mantle exhumation of the Saint Peter and Saint Paulo Peridotite Ridge, Equatorial Atlantic Ocean.

Akihisa Motoki ${ }^{1}$; Susanna Eleonora Sichel ${ }^{2}$, , Thomas Ferreira da Costa Campos ${ }^{3}$, Jennifer Angel-Amaya ${ }^{2}$, Thais Vargas ${ }^{1}$, Marcia Maia ${ }^{4}$, José Antonio Baptista Neto ${ }^{2}$, Mauro Satake Koga ${ }^{2}$, Kenji Freire Motoki ${ }^{2 ;}$ Peter Szatmari $^{5}$

1) Departamento de Mineralogia e Petrologia Ígnea, Universidade do Estado do Rio de Janeiro rochasornamentais@yahoo.com.br; 2) Departamento de Geologia, Universidade Federal Fluminense; 3) Departamento de Geologia, Universidade Federal do Rio Grande do Norte; 4) Institut Universitaire Europeen de La Mer, Brest França ; 5) CENPES, Petrobrás

Copyright 2012, SBGf - Sociedade Brasileira de Geofísica

Este texto foi preparado para a apresentação no V Simpósio Brasileiro de Geofísica, Salvador, 27 a 29 de novembro de 2012. Seu conteúdo foi revisado pelo Comitê Técnico do V SimBGf, mas não necessariamente representa a opinião da SBGf ou de seus associados. É proibida a reprodução total ou parcial deste material para propósitos comerciais sem prévia autorização da SBGf.

\section{Abstract}

This paper presents the results of recent petrographic, structural, and geotectonic studies for the Saint Peter Saint Paul Peridotite Ridge, Equatorial Atlantic Ocean. The Peridotite Ridge is divided by a graben into the North Elevation and South Elevation. The North Elevation exposes intensely deformed mylonitic peridotite and the South Elevation crops out undeformed peridotite. The Flandrian wave-cut bench and the ${ }^{14} \mathrm{C}$ datings for the carbonaceous algae indicate the active uplift rate of 1.5 $\mathrm{mm} /$ year. The tectonic fractures and the focal mechanisms of several earthquakes point out the existence of north-south compression. The compression stress is originated from the direction discordance between the transform fault and the strike-slip plate movement. In this sense, the Peridotite Ridge corresponds to the pressure ridge of the Saint Paul Transform Fault. The petrographic and structural studies indicate that the South Elevation is originated from an old megamullion and the South Elevation, an old transform fault. The both have been submitted to the active tectonic deformation of the north-south compression. The abyssal mantle of the North Elevation has been compressed, deformed, and uplifted from a sub-crustal depth up to the sea level in recent 8 million years. This peculiar tectonism is caused by the emergence of a new mid-ocean ridge segment and the consequent plate contact jump.

\section{Resumo}

Este trabalho apresenta os resultados dos estudos em petrografia, geologia estrutural e geotectônica da Cadeia Peridotítica de São Pedro São Paulo, Oceano Atlântico Equatorial. A Cadeia Peridotítica é dividida por um graben em Elevação Norte e Elevação Sul. A Elevação Norte aflora peridotito milonitizado com intensa deformação, enquanto a Elevação Sul expõe peridotito não deformado. A plataforma de abrasão marinha flandriana e as datações ${ }^{14} \mathrm{C}$ para as algas calcáreas indicam uma taxa do soerguimento ativo de 1.5 mm/ano.
As fraturas tectônicas e mecanismos focais de alguns terremotos apontam a existência do esforço de compressão norte-sul. O esforço de compressão é originado da discordância nas direções entre a falha transformante e o movimento transcorrente das placas. Neste sentido, a Cadeia Peridotítica corresponde à cadeia de pressão da Falha Transformante de São Paulo. Os estudos petrográfica e estrutural indicam que a Elevação Sul é originada de um megamullion antigo e a Elevação Norte, uma falha transformante antiga. Ambas têm sido submetidas à deformação tectônica ativa pela compressão norte-sul. O manto abissal da Elevação Norte tem sido comprimido, deformado e soerguidos desde uma profundidade sub-crustal até o nível do mar nos últimos 8 milhões de anos. Este tectonismo peculiar é causado pelo surgimento de um novo segmento de cadeia meso-oceânica e o conseqüente salto do contato de placas.

\section{Introdução}

O Arquipélago de São Pedro e São Paulo situa-se em $00^{\circ} 55^{\prime} \mathrm{N}$ e $29^{\circ} 21^{\prime} \mathrm{W}$, na região central do Oceano Atlântico Equatorial, aproximadamente $1000 \mathrm{~km}$ ao nordeste de Natal, RN. O Arquipélago ocorre no topo de uma elevação morfológica de $100 \mathrm{~km}$ de comprimento, $25 \mathrm{~km}$ de largura e $3800 \mathrm{~m}$ de altura relativa, denominada Cadeia Peridotítica de São Pedro e São Paulo. As rochas constituintes no Arquipélago são peridotito milonitizado (Tilley, 1947; Melson, 1967; Sichel et al., 2008), sendo a única exposição in-situ do manto abissal acima do nível do mar no Oceano Atlântico.

A área estudada encontra-se na zona de contato entre as placas Sul-Americana e Africana. Os mergulhos profundos em torno da Cadeia Peridotítica revelaram uma predominante quantidade de rochas peridotíticas, limitadas ocorrências de gabro, dolerito e basalto e a existência de falhas normais que constituem um graben (Hekinian et al., 2000).

As pesquisas geomorfológicas do fundo do oceano revelaram que existem, pelo menos, quatro falhas transformantes paralelas em uma faixa com largura de 80 km (Fig. 1). O movimento das falhas é do sentido sinistral com a velocidade média de $3 \mathrm{~cm} / a n o$. A região é caracterizada por intensa atividade tectônica e limitada atividade magmática. Ocorrem terremotos rasos com intensidade na escala Richter de 4.0 a 6.0. O tectonismo 
é ativo com a taxa de soerguimento de $1.5 \mathrm{~mm} / \mathrm{ano}$ (Motoki et al., 2009; Campos et al., 2010), sendo o mais intenso do Brasil.

Nos últimos anos, as pesquisas petrológicas e geotectônicas desta área estão em notável desenvolvimento com apoios financeiros da Petrobras e do CNPq. Atualmente, uma pesquisa de gravimetria está em execução.

Os autores apresentam os resultados recentes das pesquisas geotectônicas e estruturais da Cadeia Peridotítica de São Pedro e São Paulo e suas indicações sobre a origem e evolução tectônica do manto exumado.

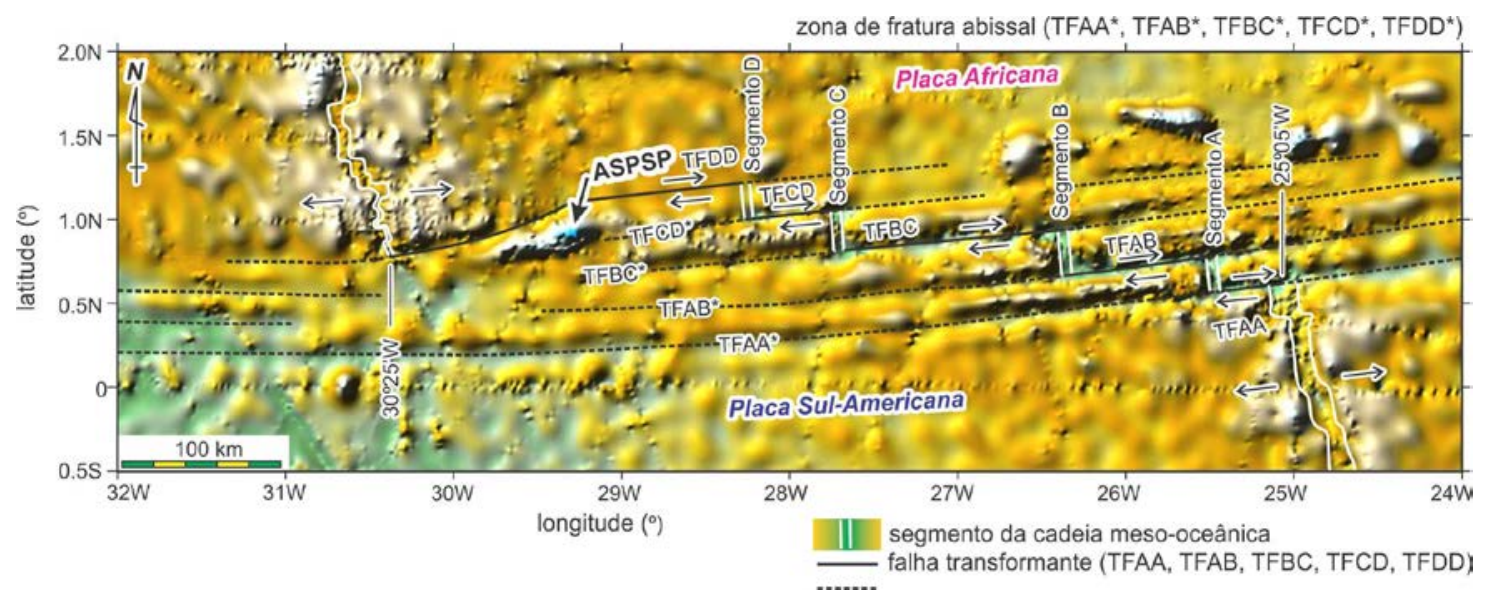

Fig. 1. Sistema de Falha Transformante e zonas de fratura abissal de São Paulo, Oceano Atlântico Equatorial.

\section{Estrutura milonítica}

As rochas ultramáficas da Elevação Norte, inclusive o Arquipélago de São Pedro e São Paulo, apresentam estrutura milonítica de tectonismo rúptil-dúctil. O mergulho é de alto ângulo, $50^{\circ}$ a $70^{\circ}$, e as direções são variáveis, de NE-SW para NNW-SSE (Fig. 2A). A estrutura milonítica é atribuída à deformação plástica originada de movimento transcorrente da falha transformante. A estrutura observada não é paralela às falhas transformantes.

Os trabalhos anteriores interpretaram que o Arquipélago situar-se-ia sobre a falha transformante TFCD, que estaria ativa. A distância entre o Arquipélago e o Segmento C é $180 \mathrm{~km}$ e a taxa de expansão da cadeia meso-oceânica é $1.5 \mathrm{~cm} / a n o$ para cada lado. Portanto, o deslocamento transcorrente dextral continuou durante 12 milhões de anos. Este tempo é suficiente para que todas as estruturas sejam redirecionadas em direção paralela à falha transformante (Fig. 2B).

Posteriormente, ocorreu uma brusca mudança no movimento da Falha Transformante TFCD que causou a perturbação da estrutura milonítica. O evento foi devido possivelmente ao surgimento de um novo segmento da cadeia, denominado Segmento D (Fig. 2C) e a conseqüente desaceleração do deslocamento dextral da TFCD. Desta forma, a Falha Transformante TFCD transformou-se na Zona de Fratura Abissal TFCD*.

O congestionamento do bloco ao lado norte da TFCD causaria a perturbação da estrutura milonítica especialmente na proximidade do contato entre a TFCD e o Segmento D. Em casos extremos, poderia ter ocorrido a inversão temporária no sentido do movimento, o que possibilita a deformação da estrutura milonítica na forma sigmoidal (Fig. 2D). As estruturas miloníticas medidas no campo são incompatíveis com o modelo da Fig. 2B, porém compatíveis com os modelos da Fig. 2C e 2D.

\section{Sistema de fraturas}

No Arquipélago de São Pedro de São Paulo, ocorre um sistema de fraturas que cortam a estrutura milonítica: 1) As sub-verticais de origem tectônica; 2) As subhorizontais de alívio de sobrecarga; 3) As de direções aleatórias de expansão volumétrica por serpentinização.

A Fig. 3 apresenta as projeções diaclases medidas no Arquipélago de São Pedro e São Paulo. As áreas A1, A2, B1 e B2 mostram concentração dos pólos de fraturas de alto ângulo de origem tectônica. A área $C$ é das fraturas de baixo ângulo de alívio de sobrecarga. As médias de direction e dip para A1 são respectivamente $334^{\circ}$ e $76^{\circ}$ para $B 1,30^{\circ}$ e $86^{\circ}$. Estas se cruzam a $64^{\circ}$ formando um sistema de fraturas conjugais com o eixo de compressão com direção N3 $\mathrm{W}$.

As fraturas que formam a concentração A2 são de $316^{\circ}$ e $75^{\circ}$ e, aquelas de B2 são de $25^{\circ}$ e $55^{\circ}$. Essas se cruzam a $69^{\circ}$ constituindo um sistema de fraturas conjugadas com o eixo de compressão $\mathrm{N} 10^{\circ} \mathrm{W}$. Ambos indicam a existência de um esforço de compressão com direção aproximadamente norte-sul com ligeira tendência para noroeste-sudoeste. 


\section{A. Estrutura milonítica}

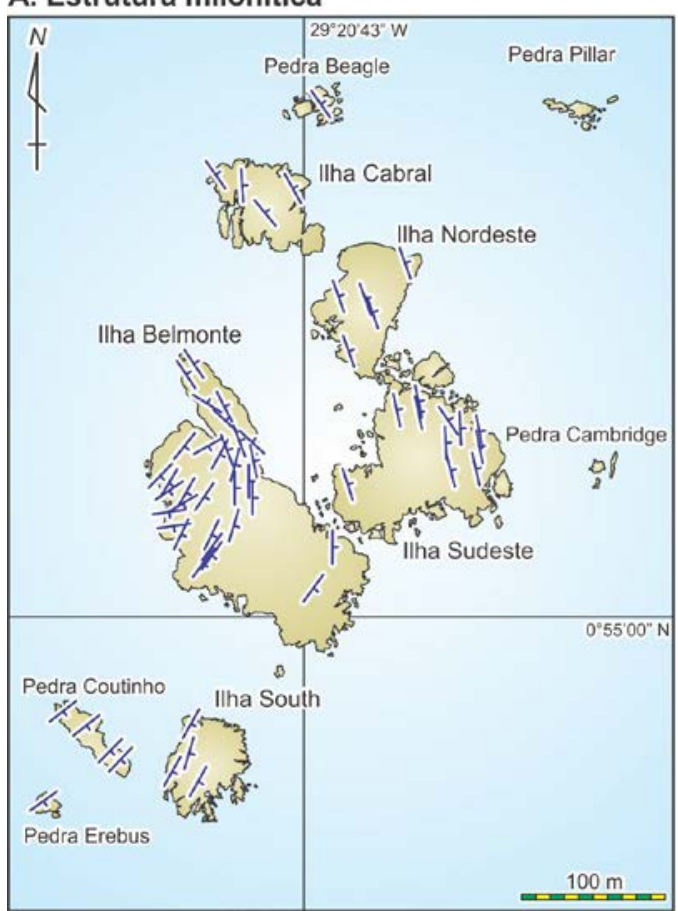

\section{B. Estrutura original}
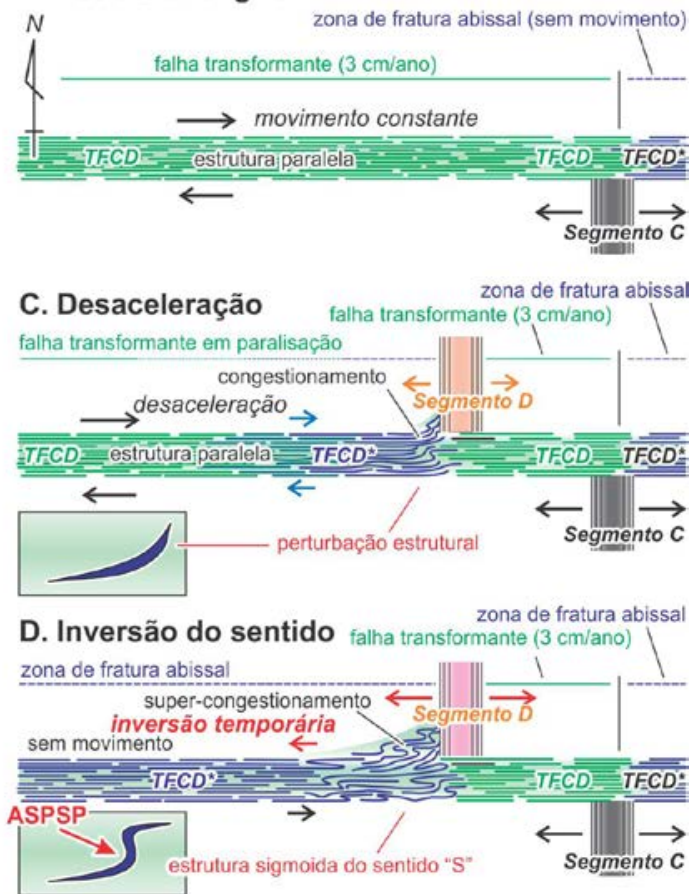

Fig. 2. Estrutura milonítica do Arquipélago de São Pedro e São Paulo (Simões et al., 2009) e sua interpretação: A) Medida no campo; B) Movimento transcorrente constante da falha transformante e a estrutura original paralela; C) Desaceleração abrupta de movimento da falha e conseqüente perturbação estrutural por congestionamento; D) Inversão temporária do sentido de movimento da falha e o conseqüente super-congestionamento, formando a estrutura sigmoidal.

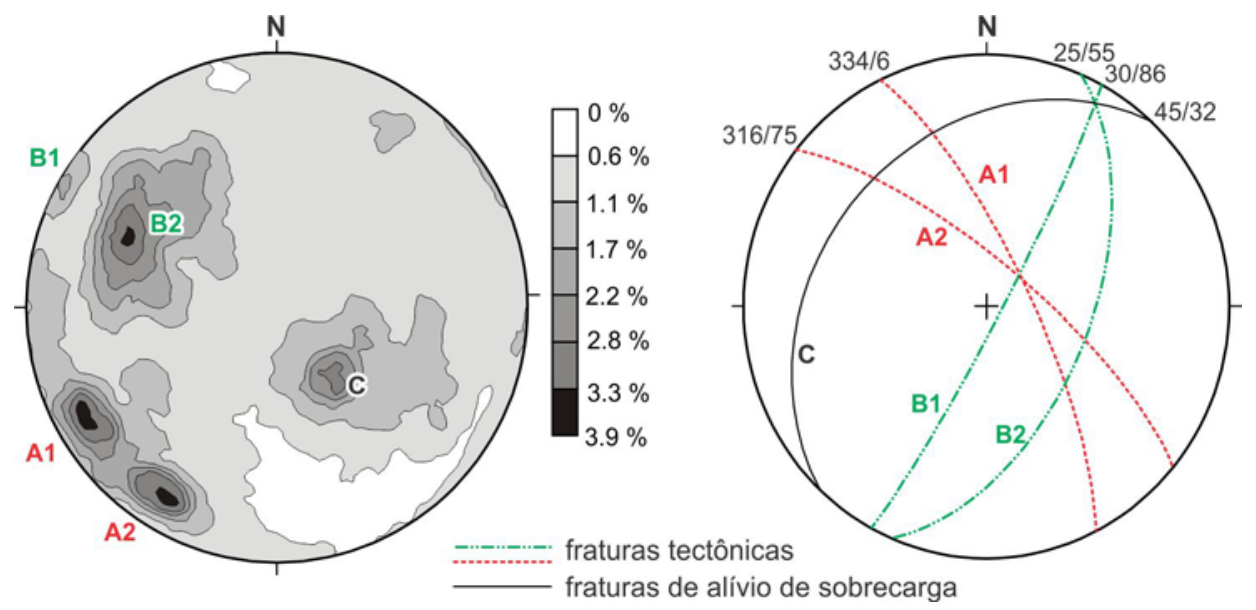

Fig. 3. Projeção estereográfica para 5438 fraturas medidas no Arquipélago de São Pedro e São Paulo (Campos et al., 2004).

\section{Mecanismo focal dos terremotos}

Entre 1971-1988, ocorreram 15 terremotos com mecanismo focal determinado (Wolfe et al., 1993; Fig. 18). Entre esses, 12 são de deslocamento transcorrente dextral com direção leste-oeste, que corresponde ao movimento das falhas transformantes do São Paulo. Um terremoto que está próximo à cadeia meso-oceânica possui o mecanismo focal de distensão, representando a expansão da cadeia meso-oceânica. Os dois terremotos no sopé da Cadeia Peridotítica apresentam o mecanismo focal de compressão norte-sul com ligeira tendência de noroeste-sudeste (Fig. 4). Desta forma, considera-se que a compressão norte-sul é ativa, sendo a força motriz do soerguimento. 


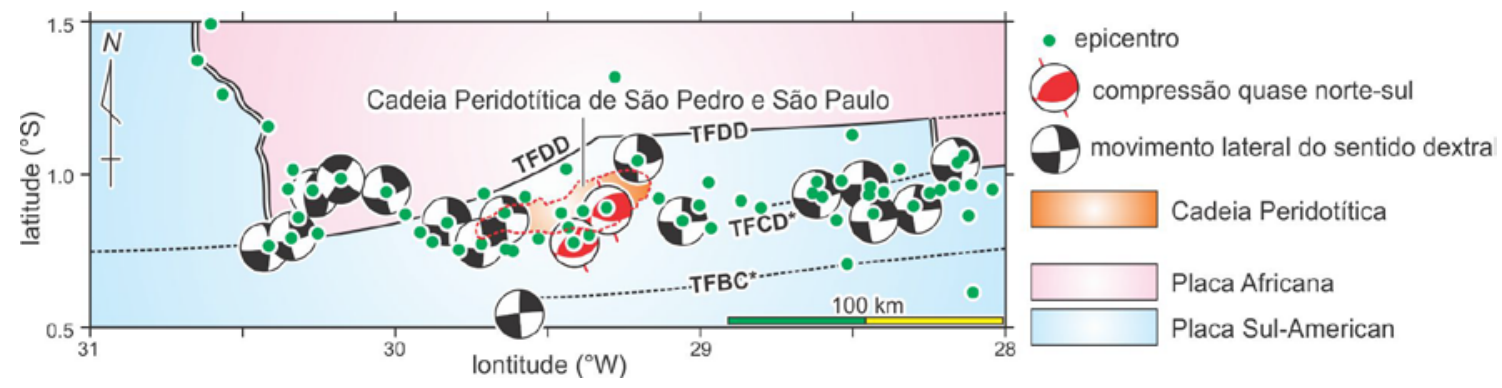

Fig. 4. Epicentros e mecanismos focais dos terremotos que ocorreram durante o período de 1971 a 1988 , conforme os dados de Wolfe et al. (1993). O contato entre a Placa Sul-Americana e a Placa Africana está de acordo com a nova interpretação do presente trabalho.

\section{Modelo de megamullion}

No final do século $X X$ ao início do $X X I$, foram encontradas as exposições de rochas ultramáficas do manto abissal no fundo do oceano em certas localidades na proximidade da cadeia meso-oceânica, formando uma saliência morfológica na forma de domo alongado, apelidada turtle carapace, com altura relativa de 1000 a 2000 m. Esta estrutura é denominada megamullion (Fig. 5; Blackman et al., 1998; Tucholke et al., 1998).

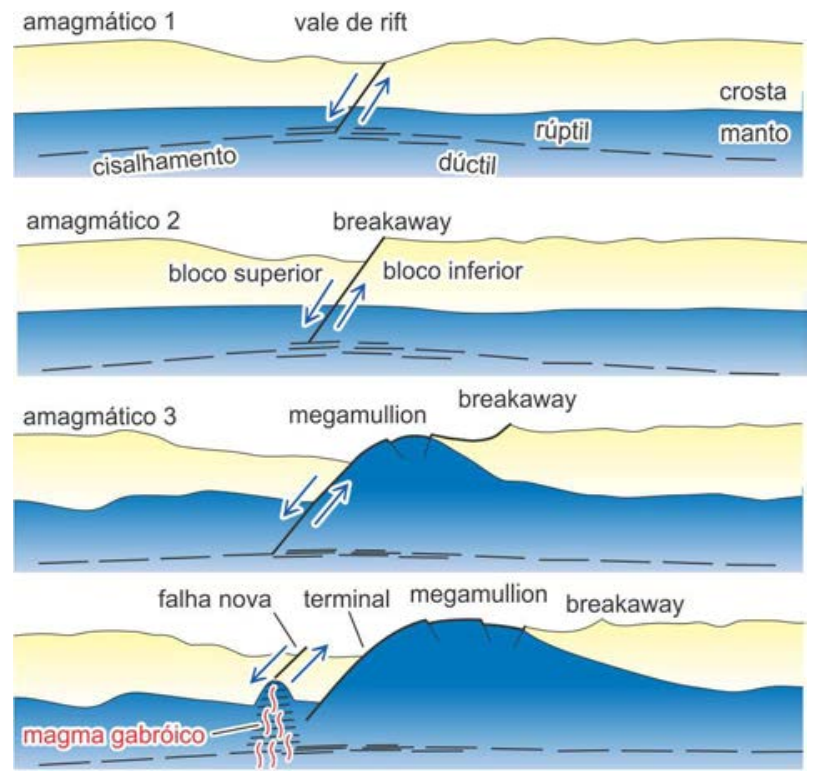

Fig. 5. Modelo de megamullions do Oceano Atlântico Norte Alternância caracterizados por alternância de peridotito e gabro, segundo Tucholke et al. (1998).

A saliência linear do megamullion é perpendicular à cadeia meso-oceânica e paralela à falha transformante. $\mathrm{Na}$ superfície desta feição, ocorrem pequenas elevações e depressões lineares com o intervalo variando de $500 \mathrm{~m}$ a $1000 \mathrm{~m}$ com altura relativa em torno de $100 \mathrm{~m}$, configuradas em direção paralela à falha transformante, chamada de corrugação (corrugation).
Uma extremidade longitudinal de megamullion está delimitada por uma falha sub-horizontal, denominada falha de descolamento (detachment fault). O bloco inferior desta falha é constituído por manto abissal exumado e o bloco superior, basalto da crosta oceânica. Tal expansão é chamada de expansão amagmática (amagmatic spreading) ou expansão tectônica (tectonic spreading).

A exposição amagmática ocorre em duas condições: 1) A expansão da cadeia meso-oceânica é de baixa velocidade; 2) O manto subjacente é de baixa temperatura. O Oceano Atlântico Equatorial tem a taxa de expansão em torno de $3.0 \mathrm{~cm} /$ ano para os dois lados. Apesar da taxa de expansão relativamente grande, ocorrem exumações do manto em certas localidades onde a temperatura do manto é anormalmente baixa.

As rochas da Cadeia Peridotítica de São Pedro e São Paulo são constituídas predominantemente por rochas ultramáficas do manto, com pequenas proporções de gabro, dolerito e basalto. Neste caso, a temperatura baixa do manto na Zona de Falhas Transformantes de São Paulo é o fator importante.

\section{A Cadeia Peridotítica é um megamullion?}

A Elevação Sul tem altura relativa de $1500 \mathrm{~m}$ e as rochas constituintes são peridotito não deformado. As batimetrias por multi-feixes mostram feições de corrugação. A Elevação Sul possui características geológicas e morfológicas de megamullion, porém sua altura é maior do que os casos normais. Considera-se que essa foi originada de um megamullion antigo e posteriormente foi deformado e soerguido pela compressão norte-sul.

Por outro lado, a altura relativa da Elevação Norte é muito grande, sendo de 3800 m, e não se pode justificar pelo modelo de megamullion. A rocha constituinte é peridotito milonítico intensamente deformado. A morfologia submarina é caracterizada por escarpas subverticais. Além disso, não se observa a morfologia indicativa de corrugação. A Elevação Norte não possui características de megamullion, porém aquelas de falhas transformantes e zonas de fratura abissal, com a exceção da saliência morfológica muito grande. Considera-se que a Elevação Norte foi originada de uma falha 
transformante antiga e foi submetida ao processo de extrema compressão, deformação e soerguimento.

\section{Evolução geotectônica}

Os trabalhos anteriores interpretavam o graben como a falha transformante ativa que marca o contato entre a Placa Sul-Americana e a Placa Africana. A Zona de Falhas Transformantes de São Paulo seria constituída por três segmentos e quatro falhas transformantes. Neste caso, o Arquipélago de São Pedro e São Paulo estaria presente na Placa Africana.

Entretanto, este graben, com $5 \mathrm{~km}$ de largura e 1200 $\mathrm{m}$ de profundidade relativa, é geomorfologicamente pequeno demais para ser uma falha transformante. Além disso, a profundidade absoluta na Cadeia Peridotítica é $2700 \mathrm{~m}$, que é menor do que a planície abissal desta região, de $3800 \mathrm{~m}$ de profundidade.

Por outro lado, cerca de $25 \mathrm{~km}$ a norte da zona de fratura TFCD*, ocorre uma depressão morfológica linear com comprimento total de $240 \mathrm{~km}$, que é sub-paralela às falhas transformantes, denominado TFDD (Fig. 1). Na metade ocidental desse, ocorrem algumas localidades mais profundas do que $4400 \mathrm{~m}$. Este trecho não é exatamente paralelo à direção de movimento relativo das placas oceânicas e é chamado de Trecho Oblíquo.

A metade oriental tem morfologia de depressão linear aparentemente ambígua devido à ausência de dados batimétricos de navios. O trecho é linear e paralelo às falhas transformantes, sendo denominado Trecho Reto.

No meio, encontra-se a inflexão em $29^{\circ} 15^{\prime} \mathrm{W}$ e na extremidade leste, em $28^{\circ} 15^{\prime} \mathrm{W}$, ocorre a morfologia sugestiva de segmento de cadeia meso-oceânica, chamada do Segmento D. Esta observação sugere o salto do contato das placas da posição da TFCD* para a TFDD conforme o surgimento do Segmento D.

Antes de $8 \mathrm{Ma}$, existia a falha transformante TFCD entre a extremidade norte do Segmento $C$ (Ponto A, Fig. 4A) e a extremidade sul da cadeia meso-oceânica de $23^{\circ} 25^{\prime} \mathrm{W}$ (Ponto B). Esta posição corresponde aproximadamente ao graben entre a Elevação Norte e Elevação Sul da Cadeia Peridotítica. A Zona de Falhas Transformantes de São Paulo era constituída por três segmentos da cadeia meso-oceânica, A, B e C, e quatro falhas transformantes TFAA, TFAB, TFBC e TFCD.
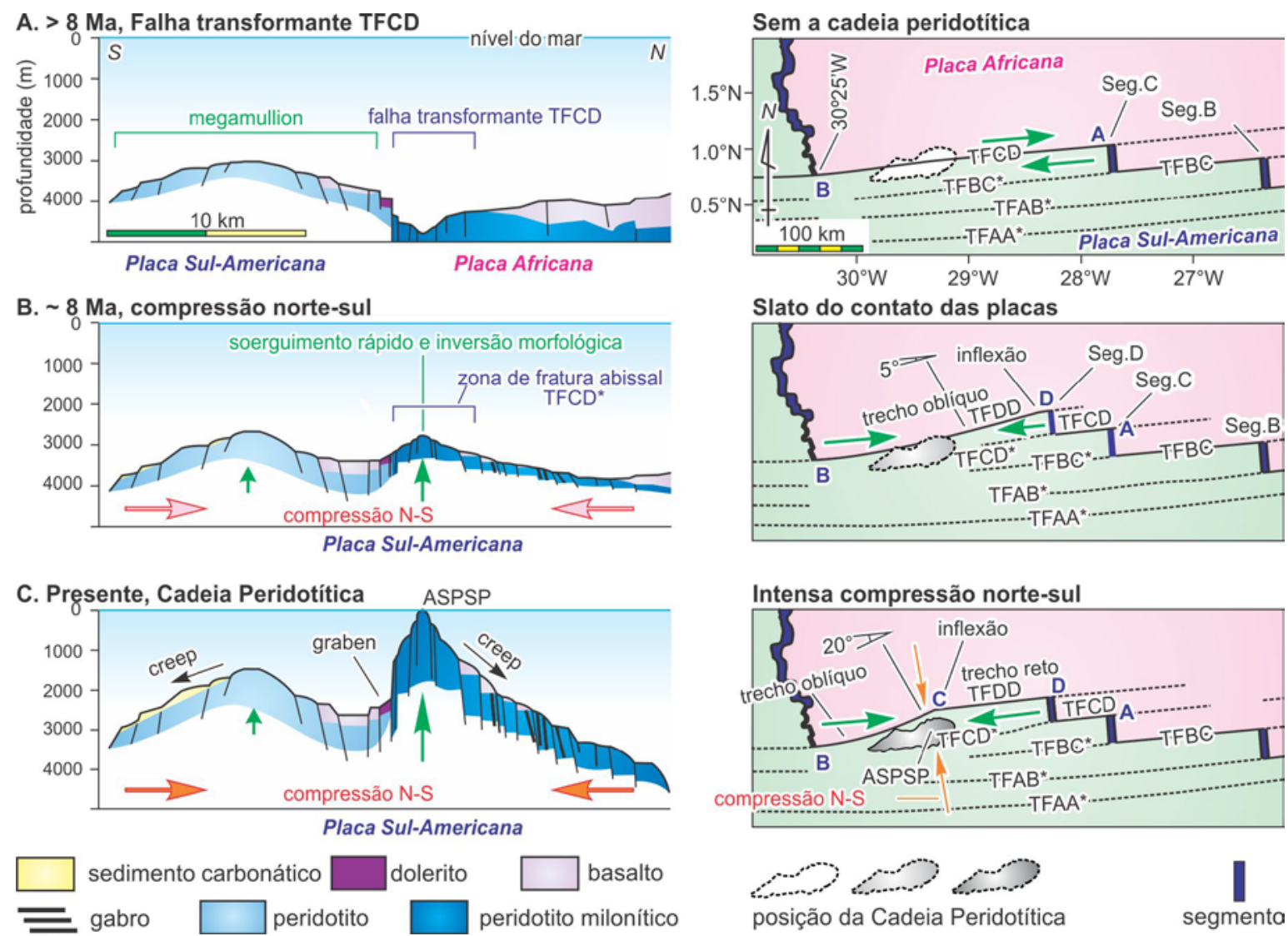

Fig. 4. llustrações esquemáticas para a origem e a evolução geotectônica da Cadeia Peridotítica de São Pedro e São Paulo, Oceano Atlântico Equatorial: A) Antes de $8 \mathrm{Ma}, 3$ segmentos da cadeia meso-oceânica da configuração convencional; B) Em torno de $8 \mathrm{Ma}$, surgimento do Segmento $\mathrm{D}$ e o salto do contato das placas de TFCD* para TFDD. O trecho oblíquo gera a compressão norte-sul e o conseqüente soerguimento da Cadeia Peridotítica; C) Presente estado, com o soerguimento acelerado da Cadeia Peridotítica. 
O bloco norte do graben era constituído por peridotito milonítico da falha transformante TFCD. O bloco sul foi composto de peridotito não deformado do megamullion. $\mathrm{O}$ trecho da falha transformante formava uma depressão morfológica linear (Fig. 4A). A estrutura milonítica da Elevação Norte foi formada nesta época através do movimento transcorrente da falha transformante.

Em $8 \mathrm{Ma}$, quando surgiu o Segmento D, ocorreu 0 salto do contado de placas a cerca de $25 \mathrm{~km}$ a norte. A falha transformante TFCD transformou-se em zona de fratura abissal TFCD*. O novo contato de placas, ou seja, a falha transformante TFDD, esteve presente entre os pontos D e B da Fig. 4B. Essa foi ligeiramente oblíqua ao movimento relativo das placas, com uma diferença angular de $5^{\circ}$. De acordo com o movimento transcorrente surgiu o esforço de compressão perpendicular ao Trecho Oblíquo, com a direção aproximada de norte-sul com ligeira tendência de NNW-SSE. Esta compressão causou o tectonismo rúptil de soerguimento e formou a primeira elevação morfológica da Cadeia Peridotítica de São Pedro e São Paulo. A taxa de soerguimento era mais baixa do que do presente.

Devido à compressão norte-sul, as rochas ultramáficas da zona de fratura abissal foram comprimidas e soerguidas. A depressão linear da falha transformou-se em uma elevação linear. Ao mesmo tempo, ocorreu o soerguimento pequeno do megamullion da Elevação Sul (Fig. 4B).

No presente, de acordo com a expansão das placas a partir do Segmento D, o Trecho Reto do TFDD estendeu em $120 \mathrm{~km}$ e o Trecho Oblíquo encurtou em $120 \mathrm{~km}$. A discordância angular entre a direção do Trecho Oblíquo e do movimento relativa das placas oceânicas aumentou para ser até $20^{\circ}$, causando o aumento do esforço de compressão norte-sul. O soerguimento da Cadeia Peridotítica foi acelerado para a taxa atual. O esforço da compressão se manifesta mais fortemente na inflexão da TFDD (Ponto C, Fig. 4C). O Arquipélago de São Pedro e São Paulo é o ponto culminante da Cadeia Peridotítica e situa-se na proximidade do ponto de inflexão. Nesta localidade, as rochas ultramáficas do manto abissal foram soerguidas desde a profundidade sub-crustal até o nível do mar, em uma distância vertical em torno de $6 \mathrm{~km}$. A Elevação Sul também foi soerguido em uma distância vertical menor, de aproximadamente de $1.5 \mathrm{~km}$. Conforme este modelo, o Arquipélago de São Pedro e São Paulo está presente atualmente na Placa SulAmericana.

\section{Agradecimentos}

Os autores agradecem à Petrobras pelo apoio financeiro através do projeto da Rede Tectônica. Gostaríamos também de agradecer ao $\mathrm{CNPq}$ e à Marinha do Brasil pela logística e suporte financeiro através do Programa Arquipélagos e Ilhas Oceânicas.

\section{Referências}

Blackman, D.K.. Cann, D.J.R., Janssen, B., Smith, D.K. 1998. Origin of extensional core complexes evidence from the Mid-Atlantic Ridge at Atlantis Fracture Zone. Journal of Geophysical Research, 103: 21315-21333.
Campos, T.F.C., Hartmann, L.A., Mata, J.M.L.S., Petra, R.A., Virganes Neto, J. 2004. Serpentinization of ultramafic rocks from the St. Peter and St. Paul Arquipelago, Equatorial Atlantic. Proceedings 32nd International Geological Congress, Firenze, Itália, CD.

Campos, T.F.C., Bezerra, F.H.R., Srivastava, N.K., Vieira, M.M., Vita-Finzi, C. 2010. Holocene tectonic uplift of the St Peter and St Paul Rocks (Equatorial Atlantic), consistent with emplacement by extrusion. Marine Geology, 271: 177-186.

Hekinian, R., Juteau, T., Gracia, E., Udintsev, G., Sichler, B., Sichel, S.E., 2000. Apprioual, R. Submersible observations of Equatorial Atlantic Mantle: The St. Paul Fracture Zone region. Marine Geophysical Research, 21: 529-560.

Melson, W.G., Jarosewich, E., Bowen, V.T., Thompsonm G. 1967. St. Peter and St. Paul rocks: a high-temperature mantle-derived intrusion. Science, 155 : 1532-1535.

Motoki, A., Sichel, S.E., Campos, T.F.C., Srivastava, N.K., Soares, R.S. 2009. Present-day uplift rate of the Saint Peter and Saint Paul Islets, Equatorial Atlantic Ocean. REM-Revista Escola de Minas, 62: 331-342.

Sichel, S.E., Esperança, S., Motoki, A., Maia, M., Horan, M.F., Szatmari, P., Alves, E.C., Mello, S.L.M. 2008. Geophysical and geochemical evidence for cold upper mantle beneath the Equatorial Atlantic Ocean. Revista Brasileira de Geofísica, 26: 69-86.

Tilley, C.E. 1947. Dunite mylonite of St. Paul's rocks (Atlantic). American Journal of Science, 245: 483-491.

Tucholke, B.E. Lin, J., Kleinrock, M.C. 1998. Megamullions and mullion structure defining oceanic metamorphic core complex on the Mid-Atlantic Ridge. Journal of Geophysical Research, 103: 9857-9866.

Wolfe, C.J., Bergman, E.A., Solomon, S.C. 1993. Oceanic transform earthquakes with unusual mechanism or locations: relation to fault geometry and state of stress in the adjacent lithosphere. Journal of Geophysical Research, 98: 16187-16211. 